\title{
Avanços Trazidos pela Lei $n$. 13.243/2016 e pela Emenda Constitucional 85 para Incentivar a Inovação nas Universidades Federais
}

\author{
Advances Brought by Law 13243/2016 and Constitutional Amendment \\ 85 to Encourage Innovation in Brazilian Federal Universities
}

\author{
Silvia Beatriz Beger Uchôa ${ }^{1}$ \\ Bruno Beger Uchôa ${ }^{2}$ \\ ${ }^{1}$ Universidade Federal de Alagoas, Maceió, AL, Brasil \\ ${ }^{2}$ Procuradoria Geral da República
}

\begin{abstract}
Resumo
O presente artigo busca compreender como a Lei n. 13.243/2016 e a Emenda Constitucional 85 podem trazer alguns avanços para incentivar as atividades de inovação nas universidades federais brasileiras. Inicialmente, são expostos os aspectos históricos ligados à criação das universidades no Brasil, que levaram essas instituições a privilegiarem os aspectos de ensino, finalidade precípua e de fundamental importância, porém distanciando-se das relações com o ambiente produtivo existente nas empresas. Diversos aspectos referentes à estruturação das universidades são citados, com atenção à legislação pertinente, por exemplo, a autonomia universitária, presente no texto da Constituição da República. Para finalizar, são trazidos os aspectos relevantes da Lei 13.243/2016, e é discutido como podem contribuir para que as pesquisas realizadas nas instituições públicas sejam desenvolvidas com maior agilidade, oportunizando um relacionamento positivo com as empresas com ganhos para toda a sociedade.
\end{abstract}

Palavras-chave: Universidades federais. Inovação. Legislação.

\begin{abstract}
This article intends to understand how Law 13243/2016 and Constitutional Amendment 85 can bring some advances to encourage innovation activities in Brazilian federal universities. Initially, it exposes the historical aspects related to the creation of the universities in Brazil, and how this led these institutions to privilege the academic aspects, primary purpose and of fundamental importance, but distancing itself from the relations with the productive environment existing in the companies. It presents several aspects related to the structure of universities, citing the relevant legislation, for example, the question of university autonomy, which is present in the text of the Brazilian Constitution. Finally, the relevant aspects of the mentioned law are brought in and how they can contribute so that the researches carried out in the public institutions can be developed with greater agility and contribute to a relationship with the companies that can bring gains for the whole society.
\end{abstract}

Keywords: Federal universities. Innovation. Law.

Área tecnológica: Inovação tecnológica. Desenvolvimento. 


\section{Introdução}

Atualmente as instituições de ensino superior (IES) no Brasil, e entre elas as universidades federais (UFs), apresentam-se em um verdadeiro dilema, conciliar as atividades de ensino às de extensão e às de pesquisa e, mais recentemente, às de inovação. Mansfield e Lee (1996) e Etzkovitz (2016) citam que a universidade é o maior responsável pela promoção da difusão do conhecimento e de técnicas que podem levar à inovação tecnológica. Em outros países, como os Estados Unidos da América, esse já é um fato sedimentado, havendo uma grande interação entre as universidades e as empresas, que buscam utilizar os conhecimentos por elas desenvolvidos.

As universidades federais são autarquias culturais (CARVALHO FILHO, 2011) e seus dirigentes têm seus atos regulamentados pelas leis federais. A Constituição da República de 1988 apresenta, em seu artigo 207, a autonomia universitária nos aspectos didáticos científicos, administrativos e de gestão financeira e patrimonial (BRASIL, 1988). Essa suposta autonomia das universidades poderia fazer com que as atividades ligadas à inovação pudessem ser facilmente administradas pela instituição. No entanto, isso não ocorre, e as universidades federais ainda encontram dificuldades para efetivar essas atividades (SCHAEFFER; RUFFONI; PUFFAL, 2015) quer seja por desconhecimento da comunidade universitária, quer seja pelas dificuldades de efetivar convênios e contratos com entidades privadas, assim como gerenciar os recursos provenientes desses acordos e convênios.

Considerando que muitas das universidades públicas brasileiras ainda estão começando a desenvolver atividades de inovação, há que se ter um arcabouço legal que possa dar sustentação a essa relação com o setor produtivo. Nesse sentido, foi criada a Lei de Inovação em 2004 (BRASIL, 2004), considerada um grande avanço, mas que ainda não respondia a todas as necessidades das UFs no sentido de possibilitar o trabalho conjunto com as empresas. A partir de erros e acertos dessa lei, foi realizado um esforço conjunto de diversas entidades ligadas à Inovação Tecnológica e, em 2011, foi proposto o Código de Ciência, Tecnologia e Inovação, resultando em uma emenda constitucional, a Emenda Constitucional 85, de 26 de fevereiro de 2016 e, em janeiro de 2016, a promulgação de uma nova Lei de Inovação (BRASIL, 2016).

Diante das dificuldades vivenciadas pela autora deste artigo, durante a sua participação como coordenadora do Núcleo de Inovação Tecnológica (NIT) da Universidade Federal de Alagoas (UFAL), por seis anos, e dos relatos encontrados na literatura especializada, pretende-se avaliar quais poderão ser os avanços trazidos pela recente lei, em relação ao estabelecido anteriormente e que poderão servir para incentivar as atividades de inovação no ambiente acadêmico.

\section{Metodologia}

O artigo foi desenvolvido inicialmente com um breve histórico sobre a criação das universidades brasileiras, e em seguida, com base em uma pesquisa em normas jurídicas, desde a Constituição Federal até as leis referentes à inovação e às universidades federais, procurando-se identificar quais as diferenças presentes na lei atual que poderão trazer benefícios às referidas instituições. Para poder conhecer as dificuldades enfrentadas pelas UFs no que se refere à inovação, foram abordados artigos diversos de periódicos, teses e dissertações que tratam do assunto. A experiência da autora na gestão de um NIT foi considerada e exemplifica-se com dados de 
depósitos de patentes realizados no Instituto Nacional da Propriedade Industrial (INPI). Trata-se de pesquisa bibliográfica, documental teórica.

\subsection{Histórico e Natureza Jurídica das Universidades Federais no Brasil}

Inicialmente, apresenta-se um breve histórico das universidades brasileiras, situando as instituições federais entre o conjunto das universidades e, em seguida, é abordada a sua natureza jurídica.

\subsubsection{Histórico Sucinto sobre a Criação das Universidades Brasileiras}

As universidades brasileiras são consideradas instituições recentes, com pouco menos de um século de existência, apesar de terem ocorrido algumas tentativas para instituir o ensino, em nível superior, desde o Brasil Colônia, como a dos jesuítas no século XIV, tendo sido negada pela Coroa Portuguesa e a que constava na agenda da Inconfidência Mineira (FAVERO, 2006). A mesma autora cita que a primeira universidade criada pelo Governo Federal foi a Universidade do Rio de Janeiro, hoje Universidade Federal do Rio de Janeiro, por meio do Decreto n. 14.343, de 7 de setembro de 1920, do Governo de Epitácio Pessoa. Apesar da criação da primeira universidade brasileira ter ocorrido somente nessa data, anteriormente havia o funcionamento de cursos superiores no Rio de Janeiro, em Minas Gerais, no Amazonas e na Bahia, sob as denominações de escolas profissionais, academias militares, academias médico-cirúrgicas, entre outras (FAVERO, 2006; BARRETO; FILGUEIRAS, 2007). As universidades começaram a ser criadas, a partir daí, mas ainda com um viés apenas de ensino, não contemplando as atividades de pesquisa e nem as de extensão (FAVERO, 2006).

Segundo o Ministério da Educação, existem 198 universidades no Brasil, sendo 104 universidades públicas (federais, estaduais e municipais) e 63 federais, o que representa quase $32 \%$ do número total (BRASIL, 2016). A seguir será explorada a natureza jurídica dessas instituições públicas federais.

\subsubsection{Natureza Jurídica das Universidades Federais Brasileiras}

As UFs brasileiras estão inseridas na Administração Pública brasileira. Administração Pública, segundo Zielienski e Costadello (2014): "[...] no sentido formal, subjetivo ou orgânico, corresponde à atuação de órgãos, entidades e agentes no exercício da função administrativa, ao passo que o sentido material, objetivo ou funcional designa a própria função administrativa". Meirelles et al. (2010) cita que: "[...] numa visão global, a Administração é, pois, todo o aparelhamento do Estado preordenado à realização de serviços, visando à satisfação das necessidades coletivas".

Considerando o sentido formal do conceito, necessita-se compreender a inserção das UFs na Administração Pública, para entender a sua natureza jurídica e quais as implicações em relação à aplicação da Lei de Inovação. O estudo da Administração Pública " [...] compreende a sua estrutura e as suas atividades, devendo partir de conceitos sobre Estado, sobre a qual repousa toda a concepção moderna de organização e funcionamento dos serviços públicos a serem prestados aos administrados." (MEIRELLES et al., 2010). 
A Administração Pública se divide em Administração Direta, que se constitui de órgãos e agentes que compõem o sistema federativo (União, estados, Distrito Federal e municípios), sendo responsáveis pelo desempenho das atividades administrativas de forma centralizada, e a Administração Indireta, composta de autarquias, sociedades de economia mista, empresas públicas e fundações públicas, que exercem a função administrativa de forma descentralizada, incumbida pela primeira de prestar determinados serviços (CARVALHO FILHO, 2011; BRASIL, 1967).

As UFs estão incluídas na Administração Indireta, na categoria de autarquia. Autarquia, segundo Carvalho Filho (2011), significa:

[...] autogoverno ou governo próprio, mas no direito positivo perdeu essa noção semântica para ter o sentido de pessoa jurídica administrativa com relativa capacidade de gestão dos interesses a seu cargo, embora sob controle do Estado, de onde se originou.

Meirelles et al. (2010) conceitua autarquias:

[...] são entes administrativos autônomos, criados por lei específica, com personalidade jurídica de Direito Público interno, patrimônio próprio e atribuições estatais específicas. São entes autônomos, mas não são autonomias. Inconfundível é autonomia com autarquia: aquela legisla para si; esta se administra a si própria, segundo as leis editadas pela entidade que a criou.

Já o Decreto-Lei n. 200/1967 define autarquia como: “[...] serviço autônomo, criado por lei, com personalidade jurídica, patrimônio e receita próprios, para executar atividades típicas da administração pública, que requeiram, para seu melhor funcionamento, gestão administrativa e financeira descentralizada." (BRASIL, 1967).

Zielinski e Costadello (2014) citam que algumas características das autarquias são consenso dos autores: serem criadas por lei; terem personalidade jurídica de direito público; possuírem capacidade de autoadministração; caracterizarem a especialização dos fins ou atividades; $e$ estarem sujeitas a controle ou tutela.

Podem ser classificadas quanto ao objeto em autarquias: assistenciais, previdenciárias, culturais, administrativas, de controle e associativas (CARVALHO FILHO, 2011). As UFs se enquadram nas autarquias culturais. Dessa forma, devem respeitar a legislação contida referente a esse tipo de entidade. Apesar de serem definidas como "serviço autônomo", as UFs não possuem autonomia, como os estados ou municípios.

Contrariamente aos aspectos expostos, a Constituição da República apresenta, em seu artigo 207: "As universidades gozam de autonomia didático-científica, administrativa e de gestão financeira e patrimonial, e obedecerão ao princípio de indissociabilidade entre ensino, pesquisa e extensão." (BRASIL, 1988). Essa suposta autonomia das universidades poderia fazer com que as atividades ligadas à inovação pudessem ser facilmente administradas pela instituição.

Ferraz (1998) cita em seu artigo:

[...] no tocante a universidades oficiais, impõe-se a evidência, o respeito aos direitos fundamentais, a observância dos princípios constitucionais que regem a administração pública direta e indireta, contidos no artigo 37. As universidades são apenas entes administrativos autônomos e não podem se sobrepor, por evidente, à ordem soberana que rege o País. 
A autonomia colocada para as UFs é, portanto, delimitada pela legislação vigente referente a essas instituições.

A partir dessas características das autarquias, procurar-se-á conhecer os aspectos da lei de inovação que podem trazer mudanças em ações nas UFs na área de inovação, facilitando aspectos de gestão de recursos oriundos de atividades de pesquisa $e$ inovação.

\subsection{A Lei n. 10.973/2004: estágio inicial da regulamentação e incentivo da inovação nas universidades federais}

Como já colocado, as universidades brasileiras foram criadas visando primordialmente ao ensino, e aos poucos, foram desenvolvendo as atividades de pesquisa e extensão universitárias, até ser introduzido o princípio da indissociablidade entre essas três atividades, na própria Constituição da República (BRASIL, 1988).

O termo inovação merece uma conceituação (BRASIL, 2016):

[...] introdução de novidade ou aperfeiçoamento no ambiente produtivo e social que resulte em novos produtos, serviços ou processos ou que compreenda a agregação de novas funcionalidades ou características a produto, serviço ou processo já existente que possa resultar em melhorias e em efetivo ganho de qualidade ou desempenho [...]

Dessa forma, a inovação tanto pode ser desenvolvida no ambiente da empresa, como ser oriunda de atividades de pesquisa desenvolvidas em Instituições de Ciência e Tecnologia (ICT), entre as quais se encontram as UFs. No entanto, para que uma pesquisa desenvolvida no âmbito da academia chegue a ser inovação, necessita ultrapassar os muros das instituições e chegar até o setor produtivo. Considerando que a inovação pode ser um meio de transformar o conhecimento em riqueza, trazendo vantagens para a instituição onde esse conhecimento foi gerado e para o País, foram editadas normas que se encontram na Lei de Inovação (BRASIL, 2016).

Pode se observar na referida legislação três grandes eixos: o estimulo à construção de ambientes especializados e cooperativos de inovação, no qual são definidos os apoios dos estados, municípios, União e Distrito Federal à realização de alianças estratégicas para desenvolvimento da inovação, compartilhamento de laboratórios de universidades, entre outros; o estímulo à participação das ICTs no processo de inovação, no qual são colocadas a possibilidade de celebração de acordos e convênios entre estas e empresas ou outras instituições públicas ou privadas, a possibilidade de remuneração de inventores nas ICTs e a adoção de criação de inventor independente; e o estímulo à inovação nas empresas (BRASIL, 2016).

O avanço mais significativo observado nas UFs foi a previsão de criação dos NITs, em seu artigo 16: "A ICT deverá dispor de núcleo de inovação tecnológica, próprio ou em associação com outras ICT, com a finalidade de gerir a sua política de inovação." (BRASIL, 2016).

As competências mínimas dos NITs foram definidas no parágrafo único do artigo 16 da Lei de Inovação (BRASIL, 2004):

São competências mínimas do núcleo de inovação tecnológica:

I. Zelar pela manutenção da política institucional de estímulo à proteção das criações, licenciamento, inovação e outras formas de transferência de tecnologia; 
II. Avaliar e classificar os resultados decorrentes de atividades e projetos de pesquisa para o atendimento das disposições desta Lei;

III. Avaliar solicitação de inventor independente para adoção de invenção na forma do art. 22;

IV. Opinar pela conveniência e promover a proteção das criações desenvolvidas na instituição;

$\mathrm{V}$. Opinar quanto à conveniência de divulgação das criações desenvolvidas na instituição, passíveis de proteção intelectual;

VI. Acompanhar o processamento dos pedidos e a manutenção dos títulos de propriedade intelectual da instituição.

A partir da criação de NIT nas UFs, pode se constatar um aumento no número de depósitos de patentes de pesquisas desenvolvidas por docentes, discentes e técnicos destas instituições (ARBIX; CONSONI, 2011). Esse panorama também se revelou na UFAL, com um crescimento na proteção por meio de depósito de patentes, levando a instituição a figurar entre os 50 maiores depositantes de patentes no País no ano de 2015, estando em $21^{\circ}$ lugar nesse ranking (INSTITUTO NACIONAL DA PROPIREDADE INDUSTRIAL, 2016).

O incentivo à realização dessa proteção pode ser observado na Tabela 1, a qual lista os depósitos no INPI realizados por oito UFs da Região Nordeste do Brasil, considerando os anos anteriores e posteriores a promulgação da Lei de Inovação (BRASIL, 2004) e o ano de criação dos NITs dessas instituições. Ressalta-se que algumas instituições já apresentavam um órgão equivalente, antes da referida lei. Percebe-se o crescimento principalmente nos últimos anos. São apresentados os dados até 2015, pois a pesquisa foi realizada em setembro de 2016. Também não foram incluídas as Universidades Federais da Bahia, de Pernambuco e do Ceará, por poderem ser consideradas de maior porte, e com número de depósitos significativamente superiores aos apresentadas no âmbito da região.

Tabela 1 - Dados de depósitos de patente no INPI de 8 UFs* do Nordeste brasileiro e ano de criação do NIT

\begin{tabular}{ccccccccc}
\hline ANo & UFS & UFAL & UFES & UFRN & UFPI & UFMA & UFPB & UFCG \\
2004 e anteriores & 9 & 0 & 0 & 3 & 0 & 0 & 13 & 0 \\
2005 & 2 & 0 & 0 & 5 & 0 & 0 & 0 & 0 \\
2006 & 0 & 0 & 0 & 6 & 0 & 0 & 5 & 0 \\
2007 & 2 & 1 & 0 & 0 & 0 & 0 & 1 & 0 \\
2008 & 2 & 0 & 2 & 3 & 2 & 0 & 2 & 0 \\
2009 & 3 & 3 & 0 & 10 & 3 & 3 & 7 & 1 \\
2010 & 4 & 6 & 3 & 4 & 2 & 4 & 4 & 0 \\
2011 & 21 & 3 & 6 & 8 & 20 & 11 & 14 & 1 \\
2012 & 12 & 6 & 3 & 19 & 13 & 6 & 9 & 0 \\
2013 & 28 & 3 & 5 & 15 & 8 & 7 & 15 & 2 \\
2014 & 22 & 6 & 15 & 26 & 13 & 6 & 13 & 0 \\
2015 & 6 & 13 & 2 & 16 & 6 & 6 & 13 & 2 \\
\hline Totais & $\mathbf{1 1 1}$ & $\mathbf{4 1}$ & $\mathbf{3 6}$ & $\mathbf{1 1 5}$ & $\mathbf{6 7}$ & $\mathbf{4 3}$ & $\mathbf{9 6}$ & $\mathbf{6}$ \\
\hline Ano de criação do NIT & 2005 & 2008 & 2008 & 2007 & 2006 & 1997 & 1982 & 2008 \\
\hline
\end{tabular}

Fonte: Elaborada pelos autores deste artigo (2016) 
Outro aspecto relevante a ser destacado se refere à possibilidade de o inventor receber uma remuneração em caso de comercialização de sua invenção, conforme o artigo 13 (BRASIL, 2004):

É assegurada ao criador participação mínima de 5\% (cinco por cento) e máxima de 1/3 (um terço) nos ganhos econômicos, auferidos pela ICT, resultantes de contratos de transferência de tecnologia e de licenciamento para outorga de direito de uso ou de exploração de criação protegida da qual tenha sido o inventor, obtentor ou autor, aplicando-se, no que couber, o disposto no parágrafo único do art. 93 da Lei n. 9.279, de 1996.

Essa possibilidade pode servir de incentivo para a participação dos funcionários públicos em realizar pesquisas voltadas para aspectos práticos de resolução de problemas técnicos da sociedade, contribuindo para o desenvolvimento tanto da instituição como do próprio País.

Neste artigo está se avaliando os avanços relativos às UFs a partir da legislação referente à inovação. No entanto, alguns autores citam a importância dessa legislação "[...] para a recuperação da indústria nacional de defesa e, por via de consequência, para a manutenção da soberania nacional." (FRIEDE; SILVA, 2010). Ou seja, esses autores consideram que a inovação pode ser entendida como um dos pilares para o desenvolvimento econômico do País.

Apesar dos avanços trazidos pela referida lei, ainda são encontradas algumas dificuldades para efetivar a introdução da inovação nas UFs, como o desconhecimento tanto dos atores internos como externos à instituição e à burocracia para a efetivação de acordos e parcerias, duração das pesquisas, localização geográfica e direitos de propriedade intelectual (SCHAEFFER; RUFFONI; PUFFAL, 2015).

A partir da experiência vivenciada pela autora deste artigo na coordenação do NIT de uma UF, podem-se descrever algumas dificuldades ainda não ultrapassadas: a primeira delas é a questão de pessoal para atuar nos NITs, pois não existe uma carreira específica para atividades ligadas à inovação nas UFs. Muitos NITs funcionaram e ainda funcionam com apoio de bolsistas, que são temporários, e apesar de se cumprir o papel de formação, inexiste a fixação desse bolsista. Essa também foi uma das questões levantadas por pesquisa realizada, além da falta de apoio institucional (SENSATO, 2014).

Quanto ao desconhecimento do setor empresarial a respeito das possibilidades de realizar parcerias para desenvolvimento das atividades de pesquisa e inovação, essa também foi verificada no âmbito da UFAL, dificultando a realização de acordos.

No que diz respeito à utilização de recursos provenientes de comercialização de tecnologias, por meio de recebimento de royalties, a dificuldade encontrada foi a realização de repasse dos benefícios aos inventores, mesmo havendo a previsão na legislação. Algumas instituições de ensino superior públicas, entre elas, UFs, já possibilitam esse recebimento, a exemplo das Universidades Federais de Minas Gerais, da Bahia, do Rio de Janeiro e de Viçosa.

A partir das modificações introduzidas na Lei de Inovação, fruto de um esforço conjunto de diversas entidades ligadas à pesquisa e inovação no Brasil, será em seguida realizada uma breve explanação do que se pode considerar que signifique avanço para diminuir os entraves enfrentados pelas UFs na área de inovação a partir das mudanças trazidas na legislação. 


\subsection{A Lei n. 13.243/2016 e a Emenda Constitucional 85: breves comentários sobre os seus avanços}

Durante 12 anos de vigência da Lei n. 10.973/2004, as diversas instituições que congregam agentes promotores da inovação no País realizaram discussões em conjunto com legisladores, para procurar o aprimoramento dos mecanismos de ação no âmbito da inovação. Exemplo dessas entidades são o Fórum Nacional dos Gestores de Inovação e Transferência de Tecnologia (FORTEC) e a Associação Nacional das Entidades Promotoras de Empreendimentos Inovadores (Anprotec), entre outras. Desse esforço, foi obtida a aprovação de uma emenda constitucional, a Emenda Constitucional 85/2015, que altera e adiciona dispositivos na Constituição Federal para atualizar o tratamento das atividades de ciência, tecnologia e inovação, introduzindo os termos referentes à inovação, ao lado dos termos ciência e tecnologia. Essa emenda é resultado de um Projeto de Lei, o PL n. 2.177/2011, que tratava da criação do Código Nacional de Ciência, Tecnologia e Inovação. A partir desse projeto, os parlamentares perceberam a necessidade de mudar o texto constitucional para amparar as mudanças propostas no referido PL (ASSOCIAÇÃO NACIONAL DAS ENTIDADES PROMOTORAS DE EMPREENDIMENTOS INOVADORES, 2015).

A partir da aprovação da Emenda Constitucional 85, em 2015, houve alguns avanços, como a possibilidade de ampliação das entidades que poderão receber apoio financeiro do poder público; ampliação das funções do Estado, por meio do estímulo à articulação entre os entes do setor, tanto públicos quanto privados, na execução das atividades de pesquisa, capacitação científica e tecnológica e inovação; cooperação dos estados, municípios e União com entes públicos e privados; e maior liberdade na administração dos recursos destinados a pesquisas, permitindo o remanejamento ou transferência de uma categoria de programação (rubrica) para outra, sem a necessidade da autorização legislativa prévia (ASSOCIAÇÃO NACIONAL DAS ENTIDADES PROMOTORAS DE EMPREENDIMENTOS INOVADORES, 2015). No entanto, o remanejamento citado ainda necessita de aprovação para ocorrer, mas em forma de ato do poder executivo (decreto), não sendo atribuição do gestor do projeto.

Depois da aprovação da Emenda Constitucional 85, as discussões continuaram, e em janeiro de 2016, houve a promulgação da Lei n. 12.343, entendida como o Código de Ciência, Tecnologia e Inovação, trazendo alterações substanciais para as instituições em consonância com as mudanças contidas na referida Emenda Constitucional.

Pode-se citar como avanços: a simplificação de procedimentos para gestão de projetos de ciência, tecnologia e inovação e a adoção de controle por resultados para avaliação desses projetos; a possibilidade de dispensa de licitação, pela administração pública, nas contratações de serviços ou produtos inovadores de empresas de micro, pequeno e médio porte; alteração da Lei n. 8.666/1993 (BRASIL, 1993) prevendo a dispensa de licitação para a contratação de bens e serviços destinados a atividades de pesquisa e desenvolvimento. No aspecto do último item, há consenso sobre as dificuldades enfrentadas por pesquisadores para aquisição de bens e serviços seguindo essa lei, sendo um avanço significativo para as UFs desenvolverem com mais agilidade as atividades de pesquisa e inovação. Traz atualização ou novas definições para diversos termos pertinentes ao assunto.

Quanto aos NITs, mantém e reforça a sua atuação nas ICTs, permitindo inclusive que possa ser constituído com personalidade jurídica própria, como entidade privada sem fins lucrativos. 
As diretrizes de sua gestão e a forma de repasse de recursos devem ser estabelecidas pela própria ICT, o que poderia trazer mais agilidade nessa gestão e contribuir para o incremento das proteções e do estabelecimento de parcerias.

Também amplia a relação com empresas, por exemplo, ao especificar a possibilidade de haver a contratação de uma empresa com exclusividade, quando o desenvolvimento da tecnologia for realizado em conjunto, sem a necessidade de ocorrer uma oferta pública. Esse item é fundamental para ampliar o interesse do setor produtivo, pois havia muita insegurança, anteriormente, para uma empresa que participava em todo o processo de desenvolvimento de um produto ou serviço inovador e que deveria ser colocado em um edital de oferta pública, depois de atingir um estágio de mercado.

Importante ponto trazido pela Emenda Constitucional 85 na relação entre a Administração Pública e as entidades privadas diz respeito aos instrumentos de cooperação, que podem ser firmados pelos entes federados com órgãos e entidades públicas e privadas, inclusive para o compartilhamento de recursos humanos especializados e capacidade instalada, para a execução de projetos de pesquisa, de desenvolvimento científico e tecnológico e de inovação, mediante contrapartida financeira ou não financeira assumida pelo ente beneficiário, na forma da lei (BRASIL, 2015).

Ainda sobre a relação entre a Administração Pública e entes privados, a Emenda Constitucional 85 dispõe que o Sistema Nacional de Ciência, Tecnologia e Inovação (SNCTI) será organizado em regime de colaboração entre entes, tanto públicos quanto privados, com vistas a promover o desenvolvimento científico e tecnológico e a inovação.

No aspecto de estímulo ao pesquisador, seja docente, em regime de dedicação exclusiva ou não, discente de graduação ou de pós-graduação, ou do corpo técnico, foi incluída a permissão para o recebimento de uma bolsa de estímulo à inovação oriunda de agências de fomento, fundação de apoio ou mesmo da própria ICT, o que antes não era permitido. Esses pesquisadores de regime de dedicação exclusiva também poderão desenvolver atividades remuneradas em empresas ou em ICT (BRASIL, 2016):

Art. 14-A. O pesquisador público em regime de dedicação exclusiva, inclusive aquele enquadrado em plano de carreiras e cargos de magistério, poderá exercer atividade remunerada de pesquisa, desenvolvimento e inovação em ICT ou em empresa e participar da execução de projeto aprovado ou custeado com recursos previstos nesta Lei, desde que observada a conveniência do órgão de origem e assegurada a continuidade de suas atividades de ensino ou pesquisa nesse órgão, a depender de sua respectiva natureza.

Apesar desses avanços, ainda muito recentes, e que deverão ser observados para avaliar a eficácia dessa legislação, somente depois da aplicação dos conceitos presentes na Emenda Constitucional 85 e na Lei n. 12.343/2016 poderão ser realmente mensurados os resultados obtidos para as UFs e para o País na Ciência, Tecnologia e Inovação. 


\section{Considerações Finais}

Procurou-se desenvolver neste artigo uma linha de pensamento sobre a evolução da prática da inovação como uma das atividades inerentes às UFs, a partir da apropriação do conhecimento gerado pelos seus pesquisadores.

Demonstrou-se que as universidades brasileiras são relativamente recentes, e que foram criadas com o propósito de formação baseada principalmente em atividades de ensino. A partir da metade do século XX, havendo início de atividades de pesquisa, de pós-graduação e de extensão, e na Constituição da República de 1988, coloca-se a indissociabilidade das vertentes ensino, pesquisa e extensão.

Apesar de algumas inciativas isoladas para a promoção da inovação nas universidades brasileiras, somente em 2004 pode se considerar que ocorreu o passo primordial para a regulamentação dessa atividade na academia, com a Lei n. 10.973/2004. Uma das iniciativas que impulsionou a inovação nas UFs, prevista nessa lei, foi a criação dos NIT, que se tornaram responsáveis pela política de inovação nas ICT e participaram ativamente na difusão dessa cultura. Mesmo ocorrendo um aumento em depósitos de patentes pelas UFs, o que mostrou um aculturamento da comunidade acadêmica, os gargalos referentes à interação com empresas, aquisição de bens e serviços para pesquisa e de remuneração de pesquisadores ainda persiste.

Visando a diminuir esses entraves às atividades de pesquisa e inovação, foram realizadas inúmeras discussões que resultaram em uma proposta do Código de Ciência, Tecnologia e Inovação, e essa proposta atualmente está em consolidação, a partir da aprovação da Emenda Constitucional 85/2015 e da Lei n. 12.343, de 2016. As mudanças estão propostas nessa legislação e espera-se que possa trazer maior agilidade e resultados às UFs e seus pesquisadores.

\section{Referências}

ASSOCIAÇÃO NACIONAL DE ENTIDADES PROMOTORAS DE EMPREENDIMENTOS INOVADORES (Anprotec). Congresso Nacional promulga PEC da inovação. Disponível em: < http://anprotec.org.br/site/2015/02/congresso-nacional-promulga-pec-da-inovacao/>. Acesso em: set. 2016.

ARBIX, Glauco; CONSONI, Flávia. Inovar para transformar a universidade brasileira. Revista Brasileira de Ciências Sociais, São Paulo, v. 26, n. 77, p. 205-251, out. 2011.

BARRETO, Arnaldo Lyrio; FILGUEIRAS, Carlos A. L. Origens da universidade brasileira. Revista Química Nova, São Paulo, v. 30, n. 7, p. 1.780-1.790, 2007.

BRASIL. Constituição (1988). Constituição da República Federativa do Brasil. Promulgada em 5 de outubro de 1988. [1988]. Disponível em: <http://www.planalto.gov.br/ccivil_03/Constituicao/ Constituicao.htm>. Acesso em: set. 2016.

Decreto-Lei n. 200, de 25 de fevereiro de 1967. Dispõe sobre a organização da Administração Federal, estabelece diretrizes para a Reforma Administrativa e dá outras providências. [1967]. Disponível em: < http://www2.camara.leg.br/legin/fed/declei/1960-1969/decreto-lei-200-25fevereiro-1967-376033-normaatualizada-pe.html> . Acesso em: out. 2016. 
Emenda Constitucional 85, de 25 de fevereiro de 2015. Altera e adiciona dispositivos na Constituição Federal para atualizar o tratamento das atividades de Ciência, Tecnologia e Inovação. [2015]. Disponível em: <http://www.planalto.gov.br/ccivil_03/Constituicao/Emendas/Emc/ emc85.htm>. Acesso em: set. 2016.

Lei n. 8.666, de 21 de junho de 1993. Regulamenta o art. 37, inciso XXI, da Constituição Federal, institui normas para licitações e contratos da Administração Pública e dá outras providências. [1993]. Disponível em: < http://www.planalto.gov.br/ccivil_03/Leis/L8666cons.htm> . Acesso em: set. 2016.

Lei n. 10.973, de 2 de dezembro de 2004. Dispõe sobre incentivos à inovação e à pesquisa tecnológica no ambiente produtivo e dá outras providências. Disponível em: <http://www. planalto.gov.br/ccivil_03/_ato2004-2006/2004/lei/110.973.htm>. Acesso em: set. 2016.

Lei n. 13.243, de 11 de janeiro de 2016. Dispõe sobre estímulos ao desenvolvimento científico, à pesquisa, à capacitação científica e tecnológica e à inovação e altera a Lei n. 10.973, de 2 de dezembro de 2004, a Lei n. 6.815, de 19 de agosto de 1980, a Lei n. 8.666, de 21 de junho de 1993, a Lei n. 12.462, de 4 de agosto de 2011, a Lei n. 8.745, de 9 de dezembro de 1993, a Lei n. 8.958, de 20 de dezembro de 1994, a Lei n. 8.010, de 29 de março de 1990, a Lei n. 8.032, de 12 de abril de 1990, e a Lei n. 12.772, de 28 de dezembro de 2012, nos termos da Emenda Constitucional n. 85, de 26 de fevereiro de 2015. [2016]. Disponível em: < http://www.planalto.gov. br/ccivil_03/_ato2015-2018/2016/lei/113243.htm>. Acesso em: set. 2016.

CARVAlHO FILHO, José dos Santos. Manual de Direito Administrativo. Rio de Janeiro: Lumen Juris. 2011.

ETZKOVITZ, Henry. Innovation lodestar: the entrepreneurial university in a stellar knowledge firmament. Technological Forecasting \& Social Change, Palo Alto, CA, v. 23, p. 122-129, 2016.

FÁVERO, Maria de Lurdes de Albuquerque. A Universidade no Brasil: das origens à Reforma Universitária de 1968. Educar, Curitiba, n. 28, p. 17-36, 2006.

FERRAZ, Anna Cândida da Cunha. Autonomia universitária. Revista PGE do Estado de SP - 10 anos da Constituição Federal. São Paulo, 1998. Disponível em: <http://www.pge.sp.gov.br/ centrodeestudos/revistaspge/revista/tes5.htm >. Acesso em: set. 2016.

FRIEDE, Reis; SILVA, André Carlos da. A Importância da Lei de Inovação. Revista CEJ, Brasília, DF, ano XIV, n. 50, p. 34-39, jul./set. 2010.

INSTITUTO NACIONAL DA PROPRIEDADE INDUSTRIAL (INPI). Boletim Mensal de Propriedade Industrial Ranking dos Depositantes Residentes 2015. 2015. Disponível em: $<$ http://www.inpi.gov.br/noticias/whirlpool-lidera-ranking-de-depositantes-de-patente-residentesnopais > . Acesso em: set. 2016.

MANSFIELD, Edwin; LEE, Jeong-Yong. The modern university: contributor to industrial innovation and recipiente of industry R\&D suport. Research Policy, [S.l.], v. 25, 7. ed., p. 1.047-1.058, 1996.

MEIRELLES, Hely Lopes et al. Direito Administrativo Brasileiro. 36. ed. São Paulo: Malheiros. 2010.

SCHAEFFER, Paola Rücker; RUFFONI, Janaina; PUFFAL, Daniel. Razões, benefícios e dificuldades da interação universidade-empresa. Revista Brasileira de Inovação, São Paulo, v. 14, n. 1, p. 105-134, jan./jun. 2015. 
SENSATO, Vanessa. Noticias INOVA Unicamp. Pesquisa realizada em parceria pela Universidade de Cambridge e UNICAMP aponta dificuldades na interação universidade empresa. 2014. Disponível em: < http://www.inova.unicamp.br/noticia/2996/> . Acesso: set. 2016.

ZIELINSKI, Diolleno Zella; COSTADELLO, Angela Cassia. Natureza e autonomia das instituições federais de ensino superior (IFES) brasileiras e os reflexos na gestão universitária. COLÓQUIO INTERNACIONAL DE GESTÃO UNIVERSITÁRIA, XIV., 3 a 5 dez. 2014, Florianópolis. Anais.... 2014. Disponível em: <https://repositorio.ufsc.br/xmlui/handle/123456789/131895>. Acesso em: out. 2016.

\section{Sobre os Autores}

\section{Silvia Beatriz Beger Uchôa}

E-mail: sbuchoa@ctec.ufal.br

Formação: Doutora em Química e Biotecnologia, pelo Instituto de Química e Biotecnologia da Universidade Federal de Alagoas (UFAL); mestre em Arquitetura e Planejamento, pela Escola de Engenharia de São Carlos da Universidade de São Paulo (USP).

Endereço profissional: Universidade Federal de Alagoas. Av. Lourival de Melo Mota, s/n., Tabuleiro do Martins - Maceió, AL. CEP: 57072-970.

\section{Bruno Beger Uchôa}

E-mail: brunouch@gmail.com

Formação: Especialista em Direito Constitucional, pela Universidade Anhanguera (Uniderp); bacharel em Direito, pelo Centro Universitário (CESMAC).

Endereço profissional: Av. General Ramiro de Noronha, 294, $1^{\circ}$ andar, Bairro Jardim Cuiabá - Cuiabá, MT. CEP: 78043-180. 